\title{
La heterogeneidad sintagmática de los adverbios en español
}

\begin{abstract}
Resumen:
El adverbio ha sido desde las primeras descripciones gramaticales por parte de los estoicos una clase heterogénea, que recogía todo lo que no era nombre, verbo o partícula. Ello ha hecho que dentro de esta clase de palabra se encuentren unidades sintagmáticamente muy diferentes, tanto unidades léxicamente plenas y expandibles como otras sin posibilidad de expansión y con contextos fijados. La presente contribución propone posibles criterios sintagmáticos con el fin de ordenar el campo de esta clase de palabra de manera similar a como se ordenan otras clases de palabras léxicas.
\end{abstract}

Palabras clave: clases de palabras, adverbios, criterios de clasificación, comportamiento sintagmático

\section{Abstract:}

\section{The Syntagmatic Heterogeneity of Spanish Adverbs}

Since the time of first grammatical descriptions made by Greek stoics, adverbs have been a very diverse class which comprises all that is neither a name nor a verb, nor a particle. Therefore, within this class of words, there are units with very different syntagmatic behaviours; for example, lexical expandable words can be found sharing the word class with others which are non-expandable and tied to single contexts. This paper proposes possible syntagmatic criteria to classify adverbs in the same way it has been done with other classes of lexical words.

Keywords: word classes, adverbs, classification criteria, syntagmatic behaviour 
1.

El término 'adverbio' arrastra, desde su acuñación por los griegos, una cierta vaguedad en lo relativo a lo designado. Entre los estoicos los adverbios tuvieron varias denominaciones, según tipos y momentos, pero

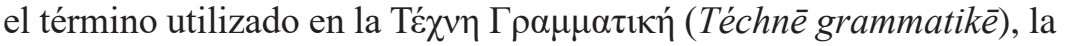
obra más influyente en la posterior gramática romana, atribuida habitualmente (aunque no unánimemente) ${ }^{1}$ a Dionisio de Tracia, fue el de

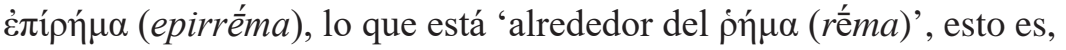
alrededor del verbo. La definición era puramente distribucional y metía en esta clase de palabra ${ }^{2}$ todo aquello que sin ser una $\sigma u ́ v \delta \varepsilon \sigma \mu o \zeta$ (syndesmos), esto es, una 'partícula', carecía de flexión. Es un tipo de etiqueta de compromiso utilizada en varias ocasiones en la gramática griega $^{3}$.

1 Véanse, sobre todo, los argumentos en contra de la autoría de Dionisio de

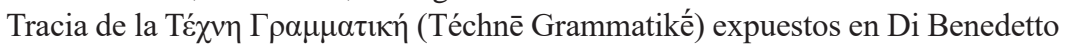
(1958-1959).

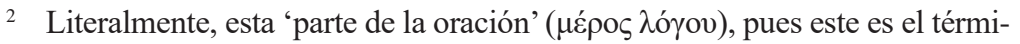
no habitual en las gramáticas clásicas para las clases de palabras, que se trasladó al latín (partes orationes) y a las gramáticas de las lenguas romances. Nebrija inauguró las gramáticas de las lenguas ‘vernáculas’ con su Gramática castellana (1492), cuyo libro cuarto tiene como título general Libro cuarto que es de syntaxi i orden delas diez partes dela oración. Esta consideración se conservaba en la propia gramática de la RAE, pues todavía en su edición de 1931, leemos: “El adverbio es la parte invariable de la oración, que sirve para calificar o determinar el significado del verbo o la del adjetivo, y a veces la de otro adverbio" (RAE, 1931: § 166). Incluso en el Esbozo, de 1973, leemos: “La distribución de las palabras en clases o partes de la oración puede hacerse con criterios morfológicos o sintácticos ...” (RAE, 1973: § 2.2.1) (negritas mías).

3 Otros términos igualmente ‘de compromiso' en la gramática griega fueron, por ejemplo, el uso de $\pi \rho 0 \theta \varepsilon \tau 1 \kappa o i ́ ~ \sigma u ́ v \delta \varepsilon \sigma \mu o t$ (partícula antepuesta) o, simplemente, $\pi \rho o ́ \theta \varepsilon \sigma 1 \varsigma$ (anteposición) para lo que los romanos traducirían como praepositio

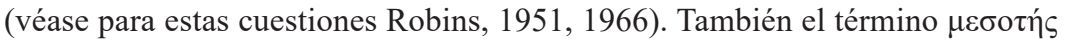
('medio') fue utilizado por los gramáticos griegos para designar valores modales

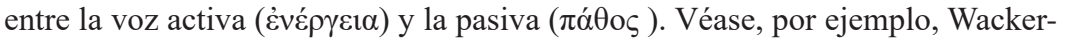

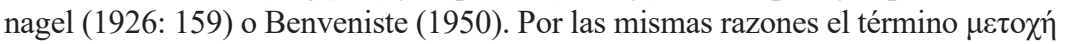
también había sido utilizado por los estoicos para denominar el participio, pues 
La vaguedad del término fue reproducida por los romanos, que tradujeron el término de modo literal como adverbum y lo definieron, como los griegos, como la parte indeclinable de la oración que añade un significado al verbo del mismo modo que el adjetivo lo hace con el nombre. Sin más precisiones ${ }^{4}$. La definición se propagó a todas las gramáticas de lenguas vernáculas, que no solo reprodujeron el término, sino también la vaguedad y generalidad del concepto: el adverbio es aquella clase de palabra que carece de flexión y modifica al verbo, al adjetivo o a otro adverbio.

\section{2.}

Visto someramente el origen de esta clase de palabra y los problemas que arrastra desde su misma acuñación, la cuestión que se plantea es la de la heterogeneidad de lo que cabe y, de hecho, se ha integrado dentro de esta noción cuya definición solamente hace referencia a su carácter de unidad morfológicamente invariable y funcionalmente modificadora de unidades verbales o intensivas (adjetivos descriptivos y adverbios) $)^{5}$. Esta laxa definición permite incluir en esta clase

estaba en medio del verbo y del nombre, ya que sintácticamente era un verbo, pero morfológicamente estaba ligado a temas de raíces nominales (Robins,

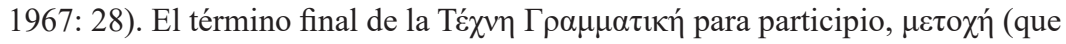
participa de rasgos del verbo y del nombre), va en la misma dirección. De este término sale el latino participium, que, como en los demás casos, se trasladará a las gramáticas posteriores.

4 De acuerdo con las Institutiones Grammaticae de Prisciano, probablemente la gramática más influyente de la época tardo-romana (sobre el año 500 d.C): "Adverbium est pars orationis indeclinabilis, cuius significatio verbis adicitur, hoc enim perficit adverbium verbis additum, quod adiectiva nomina apellativis nominibus adiuncta, ut "prudens homo prudenter agit, felix vir feliciter vivit"" (Inst. Gramat. V, I,1, apud Keil, 1855-1880: II: 60).

5 De hecho McWilliams (1954: 75) Consideraba que "A clear cut definition of the adverb, with its many overlappings with other form and function classes, is not easy. Provisionally, however, a working definition may be stated in negative terms: the adverb is that modifier of the action which is neither the actor, nor the object, nor the predicative". 
de palabra unidades sintagmáticamente muy diversas a las que, sin embargo, no se les ha encontrado hueco en otras clases de palabras 6 . Entre los adverbios encontramos unidades léxicamente plenas de carácter inequívocamente adverbial, esto es, siempre modificadoras de otra cosa (lejos, encima), al lado de otras homófonas con sustantivo de su mismo contenido y que, como adverbios, observan un comportamiento distinto a las primeras (mañana). Otros adverbios tienen su sintagmática mucho más limitada con respecto a los anteriores (apenas, todavía, entonces). Finalmente, hay otras que, dadas las limitaciones de su comportamiento, se puede dudar de su carácter adverbial (recién, casi), por no mencionar claras unidades relativas (cuando, como), o nexos estructurales (otras manifestaciones de como), que son integradas en esta clase de palabra por el simple hecho de que lo laxo de su definición admite en su seno casi todo lo que no sea nombre o verbo. Incluso los adverbios en -mente, prototipo de unidad adverbial derivativamente identificada, tienen comportamientos diversos entre sí y no deberían ser considerados como unidades uniformes: rápidamente y solamente, por poner un caso, tienen posibilidades sintagmáticas muy distintas. En suma, el adverbio ha sido, y sigue siendo, ese cajón de sastre en el que conviven unidades muy distintas entre sí, aunque calificables desde una perspectiva amplia con una misma etiqueta, junto con otras, que se alejan ya tanto de los comportamientos más prototípicos que difícilmente se justifica teóricamente su consideración de 'adverbios'. Naturalmente las gramáticas han separado los adverbios en clases, pero estas separaciones no han resuelto el problema de su heterogeneidad sintagmática, problema que no vemos en la misma medida en otras clases de palabras 'plenas' o léxicas. El sustantivo, el adjetivo o el verbo tienen uniformidad sintagmática, aunque sus distintas cualidades semánticas los hagan aptos para unos u otros con-

6 En estudios descriptivos sobre el adverbio, como el aludido hace un momento de McWilliams (1954), se incluyen como adverbios partículas interrogativas (cuánto, cómo ...), preposiciones seguidas de partícula completiva (desde que, hasta que), relativos (como, cuando, donde), supuestas locuciones diversas (con riesgo de que, en el caso de que ...) o conjunciones (aunque, ya que), entre otras unidades. 
textos. En el adverbio, en cambio, conviven unidades de lo más variado sintagmáticamente. El presente trabajo se centrará en describir, a un cierto nivel, esta heterogeneidad. Antes, sin embargo, echaremos un vistazo (necesariamente rápido y sin profundización alguna) a los criterios utilizados habitualmente para clasificar los adverbios y poner un poco de orden en ellos.

\section{3.}

Las clasificaciones de los adverbios que solemos encontrar en las gramáticas y estudios en general se rigen por cuatro criterios: (a) su valor semántico; (b) su forma, concretamente, su estructura morfológica; (c) lo que se ha llamado su naturaleza gramatical, según tengan un carácter más léxico o más gramatical, y (d) su incidencia sintáctica, entendida como el tipo de unidad al cual modifican, esto es su distribución.

3.1. En relación con su valor semántico, los adverbios tradicionalmente se han clasificado como 'de tiempo', 'de lugar' y 'de modo', pero dada la diversidad de unidades integradas en esta clase de palabra, esta clasificación se extiende a otros tipos. Álvarez Martínez (1992), por ejemplo, contempla adverbios de lugar, tiempo, modo, afirmación, negación, duda y cantidad. Kovacci (1999) convierte lo que, en principio, iba a ser un criterio gramatical en un criterio semántico, pues divide los adverbios en léxicos (bien, rápidamente, lejos, temprano, quizás ...) y pronominales (aquí, poco, segundo, donde, mismo, sí ...). La Real Academia Española, en la última edición de su gramática (RAE y ASALE, 2010), sigue la tradición, definiendo los adverbios como aquellas unidades que tienen "capacidad de establecer una relación de modificación con grupos sintácticos correspondientes a distintas categorías" ( $\$ 30.1 .1 \mathrm{a})$, y establece explícitamente los cuatro criterios arriba apuntados, a saber, A. Su estructura morfológica. B. Su significado. C. Su naturaleza gramatical y D. Su incidencia sintáctica (§ 30.1.2). Los dos últimos hacen referencia a sus capacidades gramaticales. En relación con el criterio B (semántico), la RAE adopta la 
clasificación tradicional en, 'lugar', 'tiempo', 'manera', a la que añade 'cantidad', 'afirmación' y 'negación', haciendo alusión a la existencia de clasificaciones que incluyen adverbios de 'aspecto' (todavía, completamente) (2010: § 30.1.2b).

3.2. Las clasificaciones morfológicas hacen alusión a posibles procesos derivativos en su formación. Kovacci (1999) habla de adverbios en - mente y adverbios adjetivales, como limpio, firme o claro. La RAE, de acuerdo con el criterio A de su clasificación, divide los adverbios en simples (bien, cerca, lejos, sí, entonces, etc.) y los formados con algún recurso morfológico, que guardan relación con otras clases de palabras: los formados con el sufijo -mente (los más frecuentes); los formados con preposiciones (delante, debajo, abajo, etc.); los sincréticos (comparativos) (mejor, peor, mayor, menor); los formados con afijos apreciativos (lejitos, lueguito, poquito, etc.) y, finalmente, los que denomina 'adjetivales' (bajo, fuerte, firme, seguro etc.).

3.3. En relación con su 'naturaleza gramatical' la RAE (2010: $\S 30.1 .2 c)$ los divide en léxicos y gramaticales. Son léxicos los pertenecientes a clases abiertas (adrede, bien, deprisa, regular, temprano etc.) y gramaticales los que se integran en clases cerradas. En principio este criterio se acerca a lo que podría ser una verdadera división de los adverbios como clase de palabra, pero al comprobar las subdivisiones que se establecen en estos últimos vemos que los criterios de diferenciación son más semánticos que propiamente gramaticales: así, la Real Academia Española distingue entre adverbios 'demostrativos' (aquí, allá, ahora, hoy, mañana, entonces, así), 'identificativos' o 'referenciales' (antes/después; delante/detrás; encima/debajo etc.), 'cuantificativos' (con ejemplos como muy grande, algo apartado, no me gusta demasiado), 'relativos' (cuanto, cuando, como, donde, así como los indefinidos o inespecíficos terminados en -quiera), 'interrogativos' (cuándo, cuánto, cómo, dónde y por qué), 'exclamativos’ (coincidentes en inventario con los interrogativos, aunque con diferencias de comportamiento) y, finalmente, 'de foco' o 'focales' (no, también, solo, incluso, precisamente, concretamente etc.). La naturaleza 'gramatical' 
que se anuncia en el epígrafe del criterio queda, por tanto, diluida en una clasificación semántica, cada uno de cuyos grupos integra adverbios de comportamientos sintagmáticos muy distintos. Por poner un solo ejemplo, también y concretamente tienen una sintagmática muy distinta, sin embargo, ambos están integrados en el grupo de los adverbios de foco.

3.4. El tercer criterio, lo que la RAE llama 'su incidencia sintáctica' y que en otros lugares se denomina 'criterio distribucional', clasifica los adverbios de acuerdo con los lugares que ocupan dentro del sintagma. González García (1997), por ejemplo, distingue entre adverbios 'nominales', los capaces de ocupar una función argumental dentro de la cláusula, lo cual traduce en una serie de posibilidades que negativamente se aplican a los 'no-nominales'. Kovacci (1999), por su parte, clasifica los adverbios según su función en adverbios de dictum, los que están dentro del predicado, o circunstanciales, y los que están fuera de él, los llamados "atributos oracionales" de Alarcos (1969) (Desgraciadamente, todo ha terminado) con un número bastante amplio de subdivisiones según distintos tipos de funciones, que incluyen el modus, ‘focalización’ e ‘intensificación'. La RAE (§ 30.1.2d) denomina este criterio, de carácter distribucional, como 'incidencia sintáctica' (criterio D), y, de acuerdo con él, divide los adverbios en (a) 'argumentales', esto es, los seleccionados por algún predicado como parte esencial de su significación (Pon aquí la chaqueta, Se portó estupendamente, Mide muy poco, etc. ), (b) 'atributivos', "los que desempeñan la función sintáctica de atributo” (Estamos aquí, ¿Cuándo es la reunión?, Estás estupendamente, Te veo mejor que hace un año) y (c), 'adjuntos', "es decir, modificadores, no seleccionados de verbos, adjetivos o adverbios", que son la mayor parte. (Hablar claramente, muy alto, psicológicamente endeble).

\section{4.}

Las clasificaciones anteriores, expuestas como muestra de la línea que se sigue para poner un poco de orden en el, en cierto modo, caótico 
terreno de los adverbios, no entran, sin embargo, en el problema de la heterogeneidad sintagmática, no distribucional, que encontramos en esta clase de palabra. Dejando a un lado la frecuente inclusión dentro de los adverbios de unidades que pertenecen a otro tipo de unidad, como los llamados ‘adverbios relativos' (Te enseñaré (el lugar) donde nacî) o, incluso partículas interrogativas, del tipo por qué, es evidente que dentro de aquellos cuyo carácter adverbial no suele discutirse existe una diversidad de comportamientos no recogida en las clasificaciones mencionadas. Por ejemplo, una unidad como casi ¿debe estar etiquetada del mismo modo que la unidad lejos? Y ¿ son ambas equivalentes al adverbio inequívoco rápidamente? $\mathrm{O}$, siguiendo con cuestiones relevantes para las posibilidades sintagmáticas (que no distribucionales) de los adverbios ¿Se comportan todos los terminados en -mente de igual modo? Estas y otras preguntas similares hacen referencia a las posibilidades sintagmáticas de las unidades que reciben la etiqueta de 'adverbio' y, al menos en lo que yo he alcanzado a ver, no ha habido intento de respuesta.

\section{5.}

Al igual que al clasificar los verbos (unidades unifuncionales) examinamos su complementación cuantitativa y cualitativa, parece relevante que la clasificación de los adverbios, como clase de palabra, se haga partiendo de las posibilidades sintagmáticas que genera, y no tanto de los contextos en los que aparece (clasificación distribucional). La descripción del valor sintagmático de una unidad se hace atendiendo básicamente a dos tipos de rasgos: (1) capacidad de expansión y (2) libertad contextual. Las palabras considerables como plenas, o léxicas, poseen ambos. Las unidades que han sufrido un proceso de especialización y consiguiente gramaticalización los pierden en algún grado. Las llamadas palabras estructurales y, en general, todas las unidades atonizadas (conjunciones, preposiciones, determinantes, partículas relativas) son el resultado de este proceso de especialización y limitación de posibilidades anteriores, cuando eran palabras plenas. 
La movilidad puede graduarse, pero lo relevante en cuanto a su incidencia en una palabra puede medirse en términos dicotómicos: o está indisolublemente ligada a un único contexto (las preposiciones, las conjunciones, etc. en español) o tiene la posibilidad de variar de posición dentro del sintagma en el que funciona, lo que ocurre con unidades tónicas o plenas: Ayer, Juan llegó de Varsovia; Juan llegó de Varsovia ayer; De Varsovia llegó ayer Juan, etc.

La expansión, por su parte, puede medirse distribucional y cualitativamente. La expansión distribucional divide las unidades expandidas en prenucleares o posnucleares. En, por ejemplo:

(1) Muy lejos de la ciudad,

el adverbio lejos tiene una expansión distribucionalmente prenuclear (muy) y otra posnuclear (de la ciudad). En realidad esta diferencia no es solo de posición, sino que responde a un claro reparto de funciones: la expansión adverbial prenuclear (como la adjetiva) siempre es cuantitativa o valorativa, $y$, por tanto, nunca responde a una necesidad expresiva del adverbio (una valencia). La posnuclear, en cambio, puede y suele ser una especificación pedida por el adverbio, sobre todo cuando es preposicional, con preposiciones altamente gramaticalizadas, como de, $a$ o en. En este sentido podríamos decir que la expansión prenuclear es una 'modificación sintáctica', mientras que la posnuclear expresada preposicionalmente es una 'complementación'. El orden de las expansiones, salvo en un caso concreto, tiene mucha relevancia en español, y en el caso de los adverbios, define la cualidad de las expansiones ${ }^{7}$. Además, mientras las expansiones prenucleares de

7 Como es sabido, el orden de los constituyentes sintácticos en español es muy flexible, lo que no quiere decir que sea arbitrario. El ámbito de las modificaciones se interpreta en uno u otro sentido según la colocación del modificador (Ana habla bien francés $\neq$ Ana habla francés bien). Y lo mismo con los constituyentes verbales en posición temática o remática (Yo no sé nada de eso $\neq$ No sé yo nada de eso). El único caso en el que el cambio de orden de constituyentes no afecta ni a su ámbito de influencia ni a valores informativos precisos es el de los complementos verbales extensivos posnucleares: Les regalaron caramelos a los niños $\cong$ Les regalaron a los niños caramelos. Naturalmente, de esta flexibilidad 
los adverbios (y de los adjetivos) son únicamente adverbiales, esto es, realizadas a través de adverbios valorativos (muy, harto) o modales en -mente (verdaderamente, horriblemente, constantemente, etc.), las expansiones posnucleares pueden ser preposicionales (complementarias en la mayor parte de las ocasiones), relativas o apositivas. El cuadro 1 nos muestra la distribución relativa de estos dos rasgos:

Cuadro 1: rasgos asociados a los adverbios

\begin{tabular}{|c|c|c|c|}
\hline \multicolumn{2}{|c|}{ Expansión } & \multicolumn{2}{|c|}{ Movilidad } \\
\hline \multirow{2}{*}{+} & solamente 'prenuclear' & \multirow{2}{*}{ Con distintos grados } & + \\
\cline { 2 - 2 } & 'pre-' y 'posnuclear' & \\
\cline { 1 - 2 } & - & & \\
& & \multicolumn{2}{|c|}{-} \\
\hline
\end{tabular}

Hay que destacar que, dado el distinto carácter de la expansión prey posnuclear, los adverbios que admiten la segunda siempre admitirán una cuantificación o valoración expresada prenuclearmente, pero no viceversa. Un adverbio puede admitir una valoración, pero no tener ningún tipo de 'complementación', siendo de este modo adverbios 'intransitivos', en sentido paralelo a los adjetivos 'intransitivos' o, en última instancia, a los verbos intransitivos. $\mathrm{O}$, con ejemplos, si podemos decir (2a), paralelamente al ejemplo con adjetivo (2b), podremos decir (3a). Pero decir (4a) no implica poder complementar este núcleo con expansiones posnucleares, como muestra (5):

(2a) cerca [de mi casa]

(2b) fácil [de hacer]

(3a) [muy] cerca [de mi casa]

(3b) [realmente] fácil [de hacer]

(4) $[$ muy] rápidamente

(5)*muy rápidamente de hacer

se excluyen los componentes dependientes (preposiciones, determinantes, conjunciones, relativos, clíticos...). 
Del cuadro se desprende que todos los adverbios que tienen posibilidad de expansión tienen también posibilidad de movilidad, en mayor o menor grado. E incluso algunos sin capacidad de expansión tienen cierta movilidad.

\section{6.}

Los dos rasgos del cuadro 1, en realidad, recogen los de las palabras plenas, como tales, aunque ahora lo estemos aplicando para caracterizar, de un modo todavía 'ciego', el comportamiento de las unidades definidas normalmente como adverbios. La diferencia entre palabras plenas, léxicas o tónicas, por un lado, y las estructurales o instrumentales, no léxicas o átonas, por otro es conocida, pero los límites entre unas y otras no siempre se sitúan en el mismo lugar. Hay quien considera que entre las preposiciones hay tanto átonas como tónicas ${ }^{8}$, y entre las unidades que muy habitualmente se consideran adverbios también hay unidades átonas tanto en el sentido prosódico como en el gramatical. Antes de continuar puede ser conveniente echar un vistazo a la clasificación de las palabras con la que me parece oportuno trabajar por situar cada clase en un lugar bien definido, si bien en este momento me tendré que limitar a exponer esta clasificación mediante el cuadro 2, adaptado de Jiménez Juliá (2006: 15), sin mayores justificaciones. En él destaco el contraste entre las unidades tónicas (palabras plenas o proformas tónicas) y las átonas (unidades estructurales

8 Aunque no hay una norma explícita para la consideración de una preposición como tónica, todo indica que intuitivamente las gramáticas consideran tónicas las que por razones ortográficas llevan acento. Es lo que hace la RAE (2010: § 29.2.2c), que considera que la preposición según “es la única preposición tónica del español”. La gramática catalana tiene institucionalizada la división entre preposiciones átonas ( $a$, en, amb, de, per y per $a$ ), y tónicas, todas las demás, entre las que hay mayoría de bisílabas, pero también la monosílaba fins (Badía, 1985: II: 51-87). No entro en los criterios de esta división, pero desde el punto de vista gramatical, las preposiciones románicas, en cuanto tales, son inherentemente partículas gramaticalmente átonas. 
y proformas átonas, incluyendo los clíticos, pese a su carácter subléxico y ya morfemático):

Cuadro 2: clases de palabras en español

\begin{tabular}{|c|c|c|c|c|}
\hline \multirow{4}{*}{\multicolumn{2}{|c|}{ Palabras plenas }} & \multirow{2}{*}{ nombres } & sustantivos & \multirow{6}{*}{$\begin{array}{l}\text { Unidades (considera- } \\
\text { bles) no necesariamen- } \\
\text { te gramaticalizadas }\end{array}$} \\
\hline & & & adjetivos & \\
\hline & & \multicolumn{2}{|c|}{ Verbos } & \\
\hline & & \multicolumn{2}{|c|}{ Adverbios } & \\
\hline \multirow{4}{*}{$\begin{array}{l}\text { Profor- } \\
\text { mas }\end{array}$} & \multirow{2}{*}{ tónicas } & \multicolumn{2}{|c|}{ partículas interrogativas } & \\
\hline & & \multicolumn{2}{|c|}{ Pronombres } & \\
\hline & \multirow{2}{*}{ átonas } & \multicolumn{2}{|c|}{ partículas relativas } & \multirow{6}{*}{$\begin{array}{l}\text { Unidades gramatica- } \\
\text { lizadas (en diversa } \\
\text { medida) }\end{array}$} \\
\hline & & \multicolumn{2}{|c|}{ Clíticos } & \\
\hline \multirow{4}{*}{\multicolumn{2}{|c|}{$\begin{array}{c}\text { Palabras estructu- } \\
\text { rales }\end{array}$}} & \multirow{2}{*}{$\begin{array}{l}\text { caracteriza- } \\
\text { dores }\end{array}$} & determinantes & \\
\hline & & & preposiciones & \\
\hline & & \multirow[b]{2}{*}{ nexos } & conjunciones & \\
\hline & & & $\begin{array}{c}\text { part. comple- } \\
\text { tivas }\end{array}$ & \\
\hline
\end{tabular}

De acuerdo con el cuadro, los adverbios están caracterizados como unidades no-necesariamente gramaticalizadas. Sabemos que gran parte de ellos provienen de formas sustantivas en casos oblicuos (Prósper, 1996; Mendoza, 1998: 20), pero esto, más que una gramaticalización resultaría una relexicalización, al mantener la unidad transformada propiedades léxicas y sintagmáticas de forma plena. La clase de palabra adverbio puede acoger varias subclases, pero si no queremos convertirlo en un tipo de partícula, debe mantener los rasgos que hacen de él una palabra 'plena'. Un examen, siquiera superficial al inventario de los que se consideran adverbios en las gramáticas nos permitirá ver que no siempre es así. Veamos brevemente el panorama de los adverbios en español.

7.

Como ya he mencionado antes, los adverbios han constituido un 'cajón de sastre' en el que se incluían distintas unidades cuyo comportamiento 
no les permitía integrarse en ninguna otra clase de palabra. La tradición grecorromana ha sido siempre demasiado fuerte para mover significativamente las clases de palabras con respecto a las heredadas de la Téchnē Grammatiké̄ $\bar{e}^{9}$. Incluso cuando se han separado de ellas, como Nebrija, al añadir el participio como parte separada, ha sido para reorganizar lo que ya habían descrito los griegos, y no tanto para diseñar nuevas categorías. Ello explica esa proliferación de adverbios, no solo en la gramática del español, sino en la mayoría de las gramáticas. El adverbio ha sido un 'refugio' poco comprometido, dada la vaguedad de la definición de esta clase de palabra que heredamos y con la que nos hemos mostrado respetuosos en extremo. Veamos pues los adverbios distribuidos según su comportamiento sintagmático, partiendo de los rasgos descritos en el cuadro 1. Así, distinguiremos adverbios cuyo comportamiento es el de una palabra plena (§§ 7.1-7.2) de aquellos que no pueden ser vistos como palabras plenas (§ 7.3). Dentro de uno y otro grupo hay subdivisiones atendiendo a sintagmáticas parcialmente diferentes.

7.1. En primer lugar, los adverbios plenos, esto es, los que serían los verdaderos herederos de los epirrếma griegos. Tienen algún tipo de expansión y son movibles dentro del sintagma, pues pueden caracterizar verbos u otros elementos intensivos (adjetivos u otros adverbios). Dentro de este grupo distinguimos los siguientes subgrupos:

7.1.1. Adverbios que podríamos llamar 'transitivos' o ‘transitivizables'. Es el caso de:

(6) Estamos lejos de la ciudad.

(7) Eso es mucho menos de lo que esperaba.

(8) El cine está cerca del parque.

9 No deja de ser llamativo que incluso en tradiciones gramaticales que no han seguido la terminología de raíz latina se ha hecho una adaptación de su significado para denominar el adverbio. Es el caso del término polaco przystówek, equivalente a epirrếma. 
Adverbios como lejos, menos, cerca, entre otros muchos, son palabras plenas con capacidad expansiva prenuclear (muy lejos, considerablemente menos, realmente cerca), y expansión posnuclear de tipo complementario: lejos implica siempre lejos de. Solamente cuando la referencia está implícita ('de aquí', por ejemplo) se omite. Y lo mismo podemos decir de menos o cerca. Estos adverbios son verdaderas palabras que, con sus características categoriales, se pueden poner en relación con los sustantivos, los adjetivos o los verbos, pues gozan de una libertad y unas posibilidades paralelas a las de estos. Bosque (1989: 210-211) alude a la clasificación de las preposiciones de Nebrija (de genitivo y de acusativo) para explicar su actuación, y aunque en la explicación de Bosque quedan algunas incógnitas ${ }^{10}$, señala un rasgo muy relevante, pese a estar bastante oculto a la observación directa: su posibilidad de ser aislados en predicativos o complementos de estructuras relativas, esto es, utilizando mis ejemplos, la posibilidad de decir (9-11):

(9) La ciudad de la cual estamos lejos.

(10) El amigo del que no esperaba mucho menos.

(11) El parque del cual el cine está cerca.

Este rasgo tiene que ver con la procedencia ya latina de estas formas: lejos viene de la forma laxius, comparativo del adverbio laxe, a su vez formado del adjetivo laxus; menos, viene directamente del adverbio minus y cerca del adverbio (también utilizado como preposición de acusativo) circa. Todos ellos son unidades de algún modo 'consolidadas', que gozan de un estatus pleno en toda su extensión. Ello las va a diferenciar del segundo grupo que, siendo adverbios plenos igualmente, carecen de esta posibilidad de distanciarse del modificador que las especifica apareciendo separadas de él en otras construcciones ${ }^{11}$.

${ }^{10}$ Entre ellas, que no se sabe muy bien si está analizando estas unidades como preposiciones o como adverbios.

11 Naturalmente la clasificación de unidades concretas puede estar sujeta a controversia. Es el caso de adverbios como nunca, en cuya casuística no puedo entrar ahora. 
7.1.2. Veamos los tres siguientes ejemplos:

(12) El reloj está encima de la mesa.

(13) Paseamos alrededor de la casa.

(14) El cine está delante del parque.

Aunque sincrónicamente estos adverbios parecen tener un valor similar al de los de los ejemplos (6-8), lo cierto es que su comportamiento con respecto a la 'separabilidad' difiere. Así, no parecen naturales secuencias como

(15) (?) La mesa de la que el reloj está encima.

(16) (?) La casa de la que paseamos alrededor.

(17) (?) El parque del cual el cine está delante.

Es probable que el origen reciente de estos adverbios, provenientes de construcciones preposicionales, tenga que ver con su menor probabilidad de ser tratados como una pieza independizable en la misma medida que adverbios como los de (6-8), pese a que en general su comportamiento es similar al de ellos ${ }^{12}$.

Los adverbios de estos dos grupos pueden considerarse, no obstante, adverbios 'plenos', con comportamiento sintácticamente completo, con todas las posibilidades expansivas y con total movilidad. El siguiente grupo comienza a tener algunas restricciones, aunque dentro todavía de lo que puede verse como adverbios 'plenos'.

7.1.3. Si la modificación preposicional puede verse como la prototípica de unidades nominales y, en general, la expansión por excelencia, hay un grupo de adverbios que o no la admiten o la tienen muy limitada. Se trata de adverbios como hoy, aquí, mañana, etc. Alarcos

12 No hay, de todos modos, un corte tajante entre los adverbios de $\S 7.1 .1$ y los de § 7.1.2. Así, la aceptabilidad de casos como Este traje le queda mal de mangas (el traje del que las mangas le quedan mal) y El agua está bastante bien de temperatura (el agua de la cual la temperatura está bastante bien) no parece muy clara, por lo que, pese a su carácter latino, bien podrían integrarse en este grupo y, por extensión, habría que buscar las causas de su comportamiento en factores adicionales al mero origen de los adverbios. 
(1969: 329-330) consideraba estos (y otros que considero que tienen algunas diferencias con ellos) un subtipo de nombres, pues admitían aposición y podían ser fácilmente términos de preposición. Cierto, pero sus diferencias con otros nombres son mayores que las que puede mantener con otros adverbios como los de los dos primeros grupos, por lo que, a falta de una quinta clase de palabra plena, parece más aconsejable mantenerlos dentro de los adverbios ${ }^{13}$. El rasgo distintivo de este grupo de adverbios es el de la modificación apositiva directa o especificativa (ya que una aposición explicativa, tras pausa, es posible con cualquier unidad significativa), la preposicional, $\mathrm{y}$, con ciertas limitaciones, la adverbial:

(18) Hoy día 26 /muy temprano / por la mañana saldremos de excursión.

(19) Mañana jueves/ a las cuatro es la actuación.

(20) Ocurrió aquí mismo/ en la esquina.

Adverbios como nunca (nunca jamás) o ahora (ahora mismo) podrían entrar en este grupo, si bien estas modificaciones intensificativas tienen un carácter restringido y se comportan como fórmulas cuasi fosilizadas.

Es evidente que el antes mencionado origen nominal o pronominal de los adverbios, con formas de caso oblicuo fosilizadas, tiene que notarse en muchos de ellos, que conservan hábitos típicamente nominales. Es el caso de este tercer grupo de adverbios cuya especificidad está, repito, en la modificación apositiva directa, más propia de elementos nominales.

7.1.4. Un cuarto tipo de adverbios 'transitivos' es el de los que admiten (o, en menor medida, exigen) modificación posnuclear relativa directa pues, como en el caso de las aposiciones, la relativa explicativa, tras pausa, es posible prácticamente siempre. No son muchos casos, pero son importantes y, sobre todo, son singulares. Siempre es quizá el adverbio más representativo de este grupo, pero no el único.

13 Por supuesto, se excluye el uso sustantivado de estos adverbios en casos como las mañanas, la tarde del jueves, etc. 
La locución adverbial a veces tiene un comportamiento similar, siendo, además, de los pocos casos en los que el relativo cuando aparece con antecedente explícito en español actual:

(21) Siempre que te veo me sube la moral.

(22) A veces cuando oigo esa canción me entra tristeza ${ }^{14}$

7.2. Un segundo gran tipo de adverbios es el de los 'intransitivos', esto es, de los que, admitiendo modificación prenuclear, no tienen, sin embargo, complementación. Es el caso de rápidamente/rápido u otros de los que se suelen considerar de apariencia adjetiva: firme, claro ....:

(23) Haz eso rápidamente/rápido y sin rechistar.

(24). Hay que mantener firmemente Ifirme el pulso para enhebrar la aguja

En este tipo de verbos, que incluyen estas formas 'adjetivas' y también las correspondientes en -mente (aunque unas y otras difieran en cuestiones de tendencia en relación con el orden secuencial) hay posibilidad de modificación relativa cuando el adverbio está modificado por un comparativo: haz eso lo más rápidamente que puedas, pero en este caso el núcleo de la construcción es la frase adverbial completa.

Los cuatro grupos vistos hasta ahora, tres de adverbios 'transitivos' con distintas posibilidades de complementación, y uno de adverbios 'intransitivos', con posibilidad de expansión prenuclear, pero no posnuclear, entran dentro de lo que es razonable considerar como manifestaciones de una clase de palabra de carácter pleno o léxico. Una clase muy fragmentada, pues el origen de sus integrantes es muy diverso, desde los antiguos nombres o pronombres fosilizados en ablativo u otro caso oblicuo hasta construcciones o lexicalizaciones de

14 No parece que esta estructura de relativo deba ser considerada explicativa. Desde el punto de vista prosódico la pausa no es en absoluto necesaria y, además, es distintiva con respecto a su ausencia, aunque la diferencia es sutil: A veces cuando llueve ocurre eso puede interpretarse como que 'en las ocasiones en las que llueve, algunas veces ocurre eso', mientras que a veces, cuando llueve ocurre eso, parece ser más bien que 'en algunas de las ocasiones en las que llueve ocurre eso'. 
distintos tipos, pero cuyas diferencias no justificarían un cambio de clase de unidad. Distinto es el caso de los adverbios que integrarán los siguientes apartados, pues su primera característica será la imposibilidad de expansión alguna. Ello implicará que su adscripción a una clase de palabra plena, como el adverbio, se hace solo por razones de coyuntura o de imposibilidad de encontrarle un hueco mejor, en ningún caso con criterios categoriales rigurosos.

7.3. El grupo de los adverbios 'no plenos’ está integrado por unidades muy diferentes que podemos condensar en el siguiente cuadro ${ }^{15}$ :

Cuadro 3: adverbios 'no-plenos'

\begin{tabular}{|c|c|}
\hline \multirow{2}{*}{ Con variación posicional } & Caracterizadores adverbiales \\
\cline { 2 - 2 } & Proformas de polaridad \\
\hline Con posición fija & 'Cuasipreposiciones' \\
\hline
\end{tabular}

7.3.1. Los caracterizadores adverbiales son unidades con forma adverbial (incluye alguna forma en -mente) y valor modificador de verbos, adjetivos u otros adverbios, esto es, con funciones típicamente adverbiales. Pero, bien por su evolución, o bien por su propio carácter semántico, constituyen piezas únicas, que se diferencian de las preposiciones, además de por su régimen de adjunción a las unidades que modifican, por la posibilidad de movilidad. Ejemplos de este tipo serían los ‘inequívocos’ adverbios de (25-29):

(25) Quiero saber solamente/solo una cosa.

(26) Apenas le llevó una tarde hacerlo.

(27) Era todavía un niño cuando llegó.

(28) Tampoco tú te has preocupado de ello.

(29) Los avestruces comen de todo, piedras incluso.

15 Por razones de espacio no entro en unidades perfectamente caracterizadas como otro tipo de unidad, singularmente relativos (cuando, donde, como), denominados adverbios por introducir secuencias 'adverbiales'. 
Estos adverbios actúan en la mayor parte de las ocasiones como intensificadores o matizadores de unidades concretas, sean verbales, adjetivas o adverbiales, y en menor medida como indicadores de valores funcionales ligados a la unidad verbal global, que es lo que hacen tanto los modificadores circunstanciales como los subjetivos (o, con los términos de E. Alarcos, los aditamentos o los atributos oracionales). Hay formas entre ellas que pueden ser utilizadas en varios sentidos. Tampoco o también, que funcionan indistintamente como caracterizadores adverbiales de unidades concretas o de predicaciones, pueden también actuar como proformas de polaridad intensificadoras, que trato a continuación.

7.3.2. El segundo grupo dentro de los adverbios 'no-plenos' es el de las que podemos llamar 'proformas de polaridad', que observamos claramente en (30-31):

—¿Quieres venir conmigo?

-Sí (= 'quiero ir contigo')

—No (= 'no quiero ir contigo')

(31) Juan irá a Madrid el sábado, pero Pedro no (= 'no irá a Madrid el sábado’)

Este es un grupo especial cuya movilidad, sin estar totalmente cercenada, está muy condicionada por su carácter de proforma predicativa, esto es, de elemento que sustituye toda una predicación expresando solamente la polaridad, positiva o negativa, asociada a ella. En sentido estricto podría integrarse en el grupo de las proformas tónicas, pero estas están constituidas por pronombres, personales, demostrativos e indefinidos, incluyendo en estos últimos no solo los que mantienen la flexión nominal (mucho/a/(s), otro/a(s) etc., sino también por una serie de unidades invariables con valor nominal (alguien, nadie, algo, nada etc.), sin que se haya contemplado integrar estas unidades que invariablemente sustituyen formas predicativas y no entidades nominales. Pero su naturaleza anafórica y sintácticamente autónoma es básicamente la misma en sí y en él. 
No debe confundirse el no tónico con el morfema verbal, de carácter dependiente y (obviamente) átono, de, por ejemplo:

(32) No quiero ir al cine contigo.

La polaridad es un valor inherente al verbo, y su término no marcado es el positivo. Ello hace que la polaridad positiva no se explicite, sino que vaya implícita en el verbo. Así, (32) implica (33), pero (34) solo se enuncia como tal cuando es contrastivo, y para ello carecemos de morfemas de polaridad positiva y tenemos que utilizar la proforma tónica (el llamado 'adverbio de afirmación') para reforzar contrastivamente dicha polaridad.

(33) (Yo) iré al cine contigo.

(34) (Yo) sí Tónico iré al cine contigo.

Cuando la polaridad es negativa, en cambio, se expresa explícita y morfemáticamente, según vemos en (35).

(35) (Yo) no ${ }_{\text {Atóno }}$ iré al cine contigo,

a no ser que sea contrastiva en estructuras creadas para tal fin, en cuyo caso empleamos un no tónico proformático equivalente al no de (30). Como apunté hace un momento, existen otras formas, como también y tampoco, que, siendo adverbios de otro tipo (concretamente, caracterizadores adverbiales), pueden actuar como proformas de polaridad intensificadoras. Veamos las siguientes

(36) Juan estudia física, y Pedro no (estudia física).

(37) Juan estudia física, y Pedro también (estudia física).

(38) Juan no estudia física, y Pedro sí (estudia física).

(39) Juan no estudia física, y Pedro tampoco (estudia física).

Las formas también y tampoco actúan en estas estructuras del mismo modo que sí y no. Pueden verse como formas elípticas, dentro de la llamada elipsis remática ${ }^{16}$. Estas formas pueden incluso ser parte de

16 He tratado la elipsis remática en la coordinación en Jiménez Juliá (1995: cap. IV). Aunque consideremos que ahí ‘falta’ una porción de texto, las unidades 
estructuras correctivas, como (41-44), aparentemente iguales a (40-43) pero estructuralmente diferentes:

(40) Juan estudia física, (y) no Pedro (estudia física).

(41) Juan estudia física, y también Pedro (estudia física).

(42) Juan no estudia física, y sí Pedro (estudia física).

(43) Juan no estudia física, (y) tampoco Pedro (estudia física).

En este caso las formas de polaridad, manteniendo su tonicidad, han pasado a ser parte (la parte tónica, imprescindible) de una conjunción contrastiva que revive el tipo de construcción que encontrábamos en latín con la conjunción compuesta et non $^{17}$.

Los tradicionales adverbios de afirmación o negación son, en realidad, proformas de polaridad cuya naturaleza adverbial viene fundamentalmente de su carácter invariable y su asociación con verbos, pero su afinidad con los adverbios anteriores es escasa o nula.

7.3.3. El último grupo que se puede distinguir atendiendo a los criterios mencionados en $\S 5$ es el de aquellas unidades que carecen tanto de posibilidades de expansión como de movilidad. En realidad, este es el grupo en el que de una manera más clara se cumple aquella afirmación de McWilliams (1954) aludida en $\S 2$, nota 5: lo que no es 'actor', ‘objeto' ni 'predicativo' es adverbio. Esta definición deja la puerta abierta para considerar adverbio todo tipo de palabra estructural, considerando que el adverbio es, de hecho, una palabra estructural ${ }^{18}$, por tanto, en principio, no léxica.

adverbiales 'proformáticas' siguen siendo la representación de todo el conjunto omitido.

17 Y también he tratado sobre las estructuras correctivas en Jiménez Juliá (1995: 79-83). Para las diferencias entre las estructuras correctivas (los ejemplos (40-43) y las elípticas (36-39) véanse las páginas 165-170 de ese mismo texto.

18 Según McWilliams, "The adverb is a function word" (1954: 82), y atribuye a los adverbios el rasgo definitorio de relativos e interrogativos (indirectos): "The adverbial function words are bifunctional: they introduce interrogatory and exclamatory sentences and also function within these as adverbs. At times it is difficult to distinguish between adverb and object" (ibidem). 
7.3.3.1. Dejando a un lado los excesos de McWilliams, que lleva al extremo la inclusión en esta clase de palabra de todo lo que no es claramente una unidad léxica nominal o verbal, lo cierto es que hay adverbios, sancionados como tales de forma prácticamente unánime, que, sin embargo, responden negativamente a los dos rasgos propios de una palabra plena o de carácter léxico, donde se supone que está el adverbio: su posibilidad de expansión y su movilidad. Es lo que vemos en la forma casi:

(44) Si no recuerdo mal, las últimas estadísticas (..) indican que hay un porcentaje de casi un uno y medio por ciento de jóvenes de dieciséis a veinticinco años que se pinchan

(45) El equipo lo que pasa es que nos ha ganado el corazón, nos ha ganado el corazón con un fútbol, se puede decir, casi completo, sorprendente.

(46) Yo casi prefiero ir allí, ¿sabes? ${ }^{19}$.

La forma casi puede modificar distintos tipos de palabras o sintagmas, sean frases nominales (44), adjetivos (45) o verbos (46), pero su comportamiento está mucho más próximo al de una preposición que al de un adverbio. En principio le separa de las preposiciones prototípicas la posibilidad de adjuntarse directamente a verbos, y no a través de partículas completivas (Cf. 'el hecho de que vengas', 'lo hizo sin que se enterara nadie', 'mantiene la duda de si irá o no’, etc.). Hay que observar, sin embargo, que la restricción del obligado uso de partículas completivas para que las preposiciones puedan asociarse a verbos no siempre se sigue: La preposición según se utiliza muy regularmente en el español peninsular sin partícula completiva como vemos en (47):

(47) Un documento que (...) sirve de base a una denuncia que está tramitándose en ese momento, que según tenemos entendido es un documento que encargó el propio Gobierno,

19 Todos estos ejemplos son tomados del corpus de la RAE, CREA, seleccionando "Lengua oral" y textos de España, pues de otro modo el número de ejemplos desbordaba la posibilidad de recuperarlos. La búsqueda se hizo el 15 de septiembre de 2019. 
si bien son mayoría los autores que consideran que en estos casos según ya no es una preposición, aun cuando sigue tiene otros rasgos propiamente preposicionales ${ }^{20}$. Pero, frente a la duda sobre la naturaleza categorial de según cuando va asociado directamente al verbo, y su actual tendencia a adscribirlo a otra clase, con casi no se actúa de la misma manera. Frente a (46), donde casi introduce directamente una forma verbal personal, encontramos ejemplos, de nuevo tomados de CREA, como:

(48) Para celebrar esta fiesta trataron de reunirlos a casi todos, y casi que lo lograron.

(49) Que le preguntas a un niño lo que es un churro y casi que te mira raro.

(50) Cuando me empezaron a entrevistar, casi que me molestaba más que otra cosa.

(51) Tenía la intención de pasar por el despacho a echar un vistazo al correo y casi que lo consigo.

(52) Uno de esos hechos cuyo resultado casi que justifica por sí solo la vida de un policía.

Si nos trasladamos al español de América, el uso de casi que ante verbos está generalizado, a juzgar por los ejemplos de CREA:

20 De acuerdo con la RAE y la ASALE (2010: § 29.2.2c)

"Cuando según introduce oraciones de verbo finito, no puede considerarse preposición: según dice la ley (cf. *sin lo sabe Iván: para ahorremos, etc.). Algunos gramáticos consideran conjuntivo este uso de según, pero otros entienden, como se hará aquí, que corresponde más bien al paradigma de los adverbios relativos (...) al igual que como en como dice la ley. La partícula según se comporta como otras preposiciones en otros aspectos".

Hay que indicar que en la edición de 1994 del diccionario de la RAE (Real Academia Española: 1994), todas las apariciones de según, excepto la locución conjuntiva según y como, son consideradas preposición, lo que indica que la toma de conciencia de que esta forma, habitual en el recitado escolar de preposiciones, tenía un comportamiento ajeno a otras preposiciones ha sido tardío, al menos a la hora de reflejarlo en la gramática. 
(53) Por lo que pudimos ver allí, con esa característica tan deliciosamente venezolana, donde lo ilegal se exhibe y casi que te invita a participar (Venezuela).

(54) El año pasado, a Juan Pablo Hernández le fue 'remal' en el colegio, casi que pierde el curso (Colombia).

(55) quien no exprese el malestar que siente, casi que no tendría derecho para quejarse más tarde (Ecuador),

(56) y, por tanto, casi que lo empujaron a la sombra (Bolivia),

(57) Y Francisca casi que le cierra la puerta a Fausto (Cuba).

Etc.

Sin embargo, no por ello se traslada esta unidad, al menos en los casos en los que se emplea de este modo, a la categoría de las que parece que serían sus afines: las preposiciones. Esto es, no hay un tratamiento similar a según: preposición precediendo elementos nominales, y adverbio ante verbos en forma personal. Ello puede indicar la conformidad que siempre ha existido en la gramática con la diversidad interna del adverbio, sin sentir la necesidad de poner el orden que recientemente se ha querido poner con la preposición díscola según.

7.3.3.2. Una segunda forma que entraría en este grupo de palabras con limitaciones totales en los dos parámetros establecidos sería recién, en su uso peninsular.

(58) Una sola seta, que pese apenas 50 gramos recién cogida, puede bastar para matar a un hombre.

(59) Y llamamos al perro recién comprado o recién recogido con un nombre que proyecta sobre él nuestra idea de su carácter o de su figura.

La unidad recién es una forma apocopada del adjetivo proveniente del participio de presente reciente que, como todas las (escasas) formas apocopadas que quedaron en castellano tras la eliminación de la influencia francesa que las creó en el siglo XII (buen, gran, san, muy), están fijadas como antepuestas a la unidad que modifican o caracterizan. En el caso de recién, su ámbito de modificación está muy limitado, pues solo se aplica a adjetivos de origen participial (no 
tenemos * recién feliz) y, dentro de estos, solamente a aquellos participios provenientes de verbos télicos 0 , al menos, con una aktionsart terminativa (*es una persona recién amada) ${ }^{21}$.

Naturalmente, estas limitaciones hacen que su comportamiento como otro tipo de unidad, no adverbial, por ejemplo, como preposición, resulte problemática. Pero hay que tener en cuenta que se han acogido como preposiciones unidades que tienen también fuertes restricciones: durante o mediante carecen de la posibilidad de adjuntarse a pronombres (ni oblicuos ni rectos) o verbos (ni con ni sin partícula completiva introductoria). Tienen un término limitado a elementos nominales o el pronominal neutro ello. Y no por eso dejan de ser un tipo específico de preposiciones ${ }^{22}$. Dado el comportamiento de recién en el español peninsular, sería más adecuado hacerle un hueco entre las preposiciones que en el caótico mundo de los adverbios. La única razón para que estén entre estos últimos es, precisamente la manga

21 El Manual de la RAE (RAE y ASALE, 2010) se limita a decir que la forma recién "requiere hacer referencia a algún suceso" (2010: § 27.5.5c). Y es todo lo que el volumen dice acerca de la forma recién.

${ }_{22}$ Las formas durante y mediante, una vez perdido su carácter nominal que vemos en ejemplos como mediantes las musas, tuvo su primera ubicación ¡cómo no! entre los adverbios. El Diccionario de Autoridades de la RAE dice en relación con mediante: "Usado como adverbio equivale à Respecto, en atención, por razón (...) Mediante lo cual, habian estado todos à punto de ser destruidos" (Real Academia, 1726, s.v. mediante). Las últimas ediciones de los diccionarios ya solo ubican esta forma entre las preposiciones, y en la gramática de la Real Academia leemos:

"Las preposiciones durante y mediante eran, en su origen, los participios de presente de durar y mediar, y concordaban en número con el elemento del que se predicaban: (...) Pues oyan atentos los que se admiraron / e de tales casos fizieron mención, / ca non será menos la mi narración / mediantes las musas, que a ellos guiaron (Santillana, Comedieta). Aunque queda algún resto de este uso (por ejemplo, en la expresión lexicalizada Dios mediante), las dos palabras han perdido en español actual su concordancia, su movilidad y su acento, y se han integrado en la clase de las preposiciones" (RAE y ASALE, 2010: 29.2.2).

No se alude a que la propia Real Academia, antes de su integración entre las preposiciones, los había metido en el cajón de sastre de los adverbios. 
ancha que siempre se ha aplicado para acoger en ellos todo lo que no cabía de manera natural en otro lado.

Naturalmente, estas consideraciones no incluyen el uso propiamente adverbial de recién generalizado en Hispanoamérica. Los tres siguientes ejemplos de CREA, del español ecuatoriano y argentino, son una muestra:

(60) Las lluvias de noviembre advierten la fuerza del fenómeno que recién empieza.

(61) Un vocero reconoció que recién cuatro horas después de terminada la lluvia empezaron un reconocimiento de los daños.

(62) la puerta de la bóveda donde están las cajas de seguridad estaba programada para abrirse recién el lunes a las 9.30 de la mañana.

\section{Conclusiones}

Hecho este repaso sobre la heterogeneidad sintagmática de la clase de palabra ‘adverbio’ en español, podemos terminar con las siguientes conclusiones telegráficas:

8.1. El adverbio, tal como lo hemos heredado desde el غ́лıри́ $\mu \alpha$ (epirrếma) griego, no constituye propiamente una clase de palabras, sino un conjunto de subclases definido negativamente, por su ausencia de flexión, su carácter modificador de una unidad intensiva (un verbo, un adjetivo u otro adverbio) y su mayor consistencia léxica con respecto a los $\sigma u ́ v \delta \varepsilon \sigma \mu \mathrm{ol}$ (sýndesmoi), esto es, las partículas.

8.2. Por razones históricas variadas, esta clase de palabra no fue objeto de la atención de la que disfrutó, en primer lugar, el verbo, pero también el sustantivo o el adjetivo, convirtiéndose en una especie de 'cajón de sastre' al que iban a parar gran parte de las palabras creadas por gramaticalización y que carecían de los rasgos nominales prototípicos. 
8.3. El resultado es que dentro de la clase 'adverbio' hay palabras plenas, que, tienen la posibilidad de expandirse de diversas formas, al margen de que ellas mismas tengan como función fundamental, al igual que los adjetivos, servir de expansión de otras unidades, pero también hay unidades de marcado carácter estructural (como las preposiciones o las conjunciones), que provienen de la gramaticalización de formas previas, pero que no parecía oportuno, ni incluirlas en los inventarios disponibles de palabras estructurales, ni, mucho menos, por lo costoso de la tarea, habilitar una clase nueva para ellas.

8.4. Por ello, las clasificaciones que se han hecho de los adverbios han hecho referencia a cuestiones relativamente periféricas (formas, distribución), pero no incluyen criterios que son habituales para las demás palabras plenas, como sus posibilidades expansivas o su movilidad posicional. Es cierto que se ha utilizado el criterio 'sintáctico' o, en términos de la RAE, su 'naturaleza gramatical' que permite distinguir, en principio, entre unidades léxicas y gramaticales. Pero para la clasificación de estas últimas, como vimos en $\S 3.3$, se utilizan criterios estrictamente semánticos, con lo que seguimos sin tener una clasificación propiamente gramatical de los adverbios.

8.5. En consecuencia, lo que en la presente contribución se propone es utilizar para la clasificación de los adverbios, criterios similares a los que se usan en otras palabras plenas (tónicas), esto es, su posibilidad de ser núcleo de expansiones, o no, y su carácter de palabra no-dependiente de un único contexto, determinada por cierta libertad posicional. Y, en caso de no responder positivamente a alguno de estos criterios, qué limitaciones concretas se pueden establecer para estas unidades.

8.6. Ello nos permitirá, bien subclasificar adecuadamente los adverbios, o bien, en su caso, 'reubicarlos' en otras categorías, como las preposiciones, en las que, pese a no observar todos sus rasgos prototípicos, tendrían menos diferencias con el resto de los miembros del paradigma que las observadas con otros adverbios. Y, en último término la tarea más costosa, pero probablemente más necesaria, sería 
la de replantear las categorías gramaticales, en el terreno de las palabras estructurales, pues es esta una tarea que no se ha abordado desde, como mínimo, Dionisio de Tracia (o quienquiera que fuera el autor de la Téchnē grammatikē), pese a que los procesos de gramaticalización han variado enormemente el inventario de unidades desde las formas del griego clásico en las que trabajaron.

8.7. Naturalmente, las escasas líneas que he dedicado a esta tarea no pretenden solucionar este problema, sino tan solo llamar modestamente la atención sobre él. La clasificación propuesta, y que resumo en el cuadro 4, a continuación, es solo metodológica, tentativa. Algunos adverbios (nunca, por ejemplo), podrían estar clasificados en distintos grupos dependiendo del énfasis que pusiéramos en unos u otros rasgos presentados por la unidad en cuestión. Pero la presente contribución pretende ser el punto de partida de la posibilidad de un replanteamiento, no, por supuesto, la solución de la cuestión.

El cuadro resume las divisiones tentativas que se han descrito en las líneas precedentes. Al lado de cada división he incluido el parágrafo en el que se han tratado.

Cuadro 4: Clasificación sintagmática del adverbio en español

\begin{tabular}{|c|c|c|c|}
\hline \multirow{5}{*}{$\begin{array}{l}\text { Plenos: con } \\
\text { posibilidad } \\
\text { de expansión }\end{array}$} & \multirow{4}{*}{$\begin{array}{l}\text { Modificación } \\
\text { posnuclear } \\
\text { (adverbios } \\
\text { transitivos) }\end{array}$} & \multirow[t]{2}{*}{$\begin{array}{l}\text { Preposicio- } \\
\text { nal }\end{array}$} & $\begin{array}{c}\text { § 7.1.1 Aislable en predicativos } \\
\text { /complementos de estructuras } \\
\text { relativas }\end{array}$ \\
\hline & & & § 7.1.2 No aislable \\
\hline & & \multicolumn{2}{|c|}{$\begin{array}{l}\text { § 7.1.3 Apositiva directa y preposicional/ad- } \\
\text { verbial }\end{array}$} \\
\hline & & \multicolumn{2}{|c|}{ § 7.1.4 Relativa (especificativa) } \\
\hline & \multicolumn{3}{|c|}{ § 7.2 Modificación solo prenuclear (adverbios intransitivos) } \\
\hline \multirow{3}{*}{$\begin{array}{l}\text { No plenos: } \\
\text { sin posi- } \\
\text { bilidad de } \\
\text { expansión }\end{array}$} & \multirow{2}{*}{$\begin{array}{l}\text { Con movili- } \\
\text { dad }\end{array}$} & \multicolumn{2}{|c|}{ § 7.3.1 Caracterizadores adverbiales variables } \\
\hline & & \multicolumn{2}{|c|}{ § 7.3.2 Proformas de polaridad } \\
\hline & \multicolumn{3}{|c|}{ § 7.3.3 Sin movilidad: cuasipreposiciones } \\
\hline
\end{tabular}




\section{Bibliografía}

ALARCOS LLORACH, E. (1969), “Aditamento, adverbio y cuestiones conexas", Archivum, 19 (cito por su reedición en Estudios de gramática funcional del español, Gredos, Madrid, 1980, $2^{\mathrm{a}}$ ed.), pp. 307-341.

ÁlVAREZ MARTÍNEZ, M. ${ }^{a}$ A. (1992), El adverbio, Arco Libros, Madrid. BADÍA MARGARIT, A. M. (1985), Gramática catalana, (2 vol.), Gredos, Madrid.

BENVENISTE, E. (1950), “Actif et moyen dans le verbe”, Journal de Psychologie, reed., en: Problémes de linguistique générale, Gallimard, Paris, 1966, pp. 168-175.

BOSQUE, I. (1989), Las categorías gramaticales. Relaciones y diferencias, Síntesis, Madrid.

DI BENEDETTO, V. (1958-1959), "Dionisio Trace e la Techne a lui attribuita“, Annali della Scuola Normale Superiore di Pisa (Classe di Lettere e Filosofia), 7, pp. 169-710.

GONZÁLEZ GARCÍA, L. (1997), El adverbio en español, Universidade da Coruña. Servicio de Publicacións, A Coruña.

JIMÉNEZ JULIÁ, T. (1995), La coordinación en español. Aspectos teóricos y descriptivos, Anejo de Verba, $\mathrm{n}^{\circ}$ 36, Universidade de Santiago de Compostela, Santiago de Compostela.

JIMÉNEZ JULIÁ, T. (2006), El paradigma determinante. Origen nominativo, formación y características, Anejo de Verba, ${ }^{\circ}$ 56, Universidade de Santiago de Compostela, Santiago de Compostela.

KEIL, H. (ed.) (1855-1880), Gramatici latini, (7 vol.), Georg Holms Verlagsbuchhandlung, Hildesheim (Rep. 1961).

KOVACCI, O. (1999), "El adverbio”, en: Bosque, I., Demonte, V. (dirs.), Gramática descriptiva de la lengua española, vol. I, Espasa Calpe, Madrid, pp. 705-786.

MCWILLIAMS, R. D. (1954), “The Adverb in Colloquial Spanish”, en: Kahane, H. R., Pietrangeli, A. (eds.), Descriptive Studies in Spanish Grammar, The University of Illinois Press, Urbana, pp. 73-138.

MENDOZA, J. (1998), "Las raíces pronominal-adverbiales. Partículas y conjunciones. Adverbios, preverbios y adposiciones”, en: Adrados, F. R., 
Bernabé, A., Mendoza, J., Manual de lingüística indoeuropea, vol. III, Ediciones Clásicas, Madrid, Cap. 8.

PRÓSPER, B. (1996), "Los adverbios de origen nominal y el problema de la heteróclisis *-r/*-n”, Emerita, 64 (1), pp. 113-135, https://doi.org/10.3989/ emerita.1996.v64.i1.251.

REAL ACADEMIA ESPAÑOLA (1963 [1726]), Diccionario de autoridades, Edición Facsímil, Gredos, Madrid.

REAL ACADEMIA ESPAÑOLA (1931), Gramática de la lengua española, Nueva edición reformada, Espasa-Calpe, Madrid.

REAL ACADEMIA ESPAÑOLA (1973), Esbozo de una nueva gramática de la lengua española, Espasa-Calpe, Madrid.

REAL ACADEMIA ESPAÑOLA (1994), Diccionario de la lengua española, ( $21^{\text {a }}$ edición), RAE/Espasa Calpe, Madrid.

REAL ACADEMIA ESPAÑOLA, ASOCIACIÓN DE ACADEMIAS DE LA LENGUA ESPAÑOLA (2010), Nueva Gramática de la lengua española. Manual, Asociación de Academias de la Lengua Española / Espasa Libros, Madrid.

ROBINS, R. H. (1951), Ancient \& Mediaeval Grammatical Theory in Europe (with Particular Reference to Modern Linguistic Doctrine), Bell, London, https://doi.org/10.2307/627674.

ROBINS, R. H. (1966), "The Development of the Word Class System of the European Grammatical Tradition", Foundations of Language, 2, pp. 3-19, https://doi.org/10.1515/9783110588972-047.

ROBINS, R. H. (1967), A Short History of Linguistics, Longman, London. WACKERNAGEL, J. (2009 [1926]), Lectures on Syntax with Special Reference to Greek, Latin, and Germanic, Oxford University Press, Oxford.

\section{Corpus consultado:}

REAL ACADEMIA ESPAÑOLA: Corpus de referencia del español actual (Banco de datos CREA), [on-line] http://www.rae.es, 15.09.2019. 